\title{
DESEMPENHO OPERACIONAL DE UM PROTÓTIPO “AEROSSOLO”
}

\author{
AFONSO LOPES ${ }^{1}$, FELIPE T. DA CAMARA ${ }^{2}$, NEWTON LA SCALA JÚNIOR ${ }^{3}$, \\ CARLOS E. A. FURLANI ${ }^{4}$, ROUVERSON P. DA SILVA ${ }^{5}$, ANA L. P. B. BARBOSA ${ }^{6}$
}

\begin{abstract}
RESUMO: O desempenho operacional de máquinas e equipamentos agrícolas é de fundamental importância para o conhecimento do comportamento desses em condições de trabalho. O presente estudo teve por objetivo avaliar o desempenho operacional de um protótipo "Aerossolo", tracionado por um trator Valtra BM100 4x2 TDA, com potência no motor de 73,6 kW (100 cv). O equipamento é de arrasto, constituído por comando hidráulico, cabeçalho com luva telescópica para regulagem longitudinal, duas seções dispostas lateralmente, contando com 28 lâminas em cada uma delas, lastros de concreto, rodas de transporte e rolo destorroador. O trabalho foi conduzido no Departamento de Engenharia Rural da UNESP - Jaboticabal, em delineamento em blocos casualizados, no esquema fatorial $3 \times 3$, com quatro repetições. A combinação dos nove tratamentos deu-se por três condições de lastragens $(0 ; 960$ e $1.307 \mathrm{~kg})$ e três ângulos das seções $\left(0^{\circ} ; 7^{\circ}\right.$ e $\left.14^{\circ}\right)$. Os resultados evidenciaram aumento de $32,4 \%$ no consumo operacional (L há ${ }^{-1}$ ) relacionado à maior lastragem, bem como em $26,8 \%$ com o maior ângulo das seções, ambos comparados à condição sem lastro e com menor ângulo, respectivamente. A profundidade de trabalho, a força de tração e a potência na barra aumentaram com o aumento do ângulo das seções e com a adição de lastros.
\end{abstract}

PALAVRAS-CHAVE: força de tração, velocidade de deslocamento, consumo de combustível.

\section{OPERATIONAL PERFORMANCE OF AN “AEROSSOLO” PROTOTYPE}

\begin{abstract}
It is been a great deal of interest the studying of the operational performance of tractors and its machinery especially in work conditions. The present study had as objective to evaluate the operational performance of an "Aerossolo" prototype tracked with a Valtra BM100 4x2 TDA, with the engine power of $73.6 \mathrm{~kW}(100 \mathrm{cv})$. The prototype equipment is a drag type, hydraulically commanded, with telescopic heading for longitudinal adjustment, two lateral sections with 28 knifes in each one of them, concrete ballasts, wheels of transport and aggregate breaker coil. The work was conducted in the Department of Agricultural Engineering of the UNESP, Jaboticabal Campus, in a randomized blocks design, factorial $3 \times 3$, with four repetitions. The nine studied treatments were a combination for three ballast conditions $(0 ; 960$ and 1,307 kg) and three angles of the sections $\left(0^{\circ} ; 7^{\circ}\right.$ and $\left.14^{\circ}\right)$. The results indicate an increase in operational consumption (liters per hectare) of $32.4 \%$ in relation to the concrete ballast addition, and a $26.8 \%$ in relation to the angle variation between sections. The working depth, traction force and power demands were higher with the increases in the concrete ballast and the angle variation between sections.
\end{abstract}

KEYWORDS: traction force, forward speed, fuel consumption.

\footnotetext{
${ }^{1}$ Eng ${ }^{\mathrm{o}}$ Agrícola, Prof. Adjunto, Departamento de Engenharia Rural, FCAV/UNESP, Jaboticabal - SP, Fone: (0XX16) 3209.2637, afonso@fcav.unesp.br, Bolsista de Produtividade CNPq.

${ }^{2}$ Eng $^{\mathrm{o}}$ Agrônomo, Prof. Adjunto, Universidade Federal do Ceará, Câmpus do Cariri, Juazeiro do Norte - CE, felipetdacamara@yahoo.com.br

${ }^{3}$ Físico, Prof. Dr., Departamento de Ciências Exatas, FCAV/UNESP, Jaboticabal - SP.

${ }^{4}$ Eng $\mathrm{o}$ Agrônomo, Prof. Adjunto, Departamento de Engenharia Rural, FCAV/UNESP, Jaboticabal - SP, Fone: (0XX16) 3209.2637, furlani@fcav.unesp.br, Bolsista de Produtividade CNPq.

${ }^{5}$ Eng ${ }^{\circ}$ Agrícola, Prof. Adjunto, Departamento de Engenharia Rural, FCAV/UNESP, Jaboticabal - SP, Fone: (0XX16) 3209.2637, rouverson@fcav.unesp.br, Bolsista de Produtividade CNPq.

${ }^{6}$ Eng ${ }^{\mathrm{a}}$ Agrônoma, Doutoranda em Ciência do Solo, Departamento de Engenharia Rural, FCAV/UNESP, Jaboticabal - SP.

Recebido pelo Conselho Editorial em: 20-8-2008

Aprovado pelo Conselho Editorial em: 21-11-2009
} 


\section{INTRODUÇÃO}

O interesse em aumentar a produtividade e reduzir os custos de produção, bem como a preocupação com a qualidade e a preservação do meio ambiente implicam necessidade do desenvolvimento de novos equipamentos agrícolas destinados ao preparo do solo. Ressalta-se, também, que os atrativos dessas inovações levam em consideração o menor consumo de combustível do trator e o maior desempenho operacional, mantendo ou melhorando a qualidade das operações.

Neste contexto, as operações de preparo de solo são de vital importância, pois, segundo HAKANSON (1994), essas são um dos componentes mais importantes do custo de produção e influenciam na maioria das propriedades físicas e químicas do solo, assim como afetam os processos biológicos e condicionam o estabelecimento e a produção das culturas.

De acordo com a ASAE (1997), na norma ASAE EP 291.1, os sistemas de preparo do solo são enquadrados em categorias definidas, a saber: a) preparo convencional, que seria a combinação de duas ou mais operações; b) preparo reduzido, apenas uma operação, e c) semeadura direta, semeadura em solo não preparado.

Em sistemas de preparo convencional, a aração é uma operação básica, em que o arado é um equipamento que corta, eleva, inverte e esboroa as leivas, de modo a deixar a superfície do solo voltada para baixo (FURLANI, 2000). O movimento rotativo dos discos faz com que os mesmos girem cortando o solo e a vegetação (GADANHA JÚNIOR et al., 1991). Os mesmos autores relataram que a grade de disco leve, também denominada de niveladora, é utilizada para promover a mobilização superficial do solo após a aração, destorroando e uniformizando o microrrelevo para a operação de semeadura.

DALLMEYER (1994) cita que o preparo reduzido, por não inverter as leivas do solo, proporciona menor incorporação de resíduos vegetais em menor número de operações, sendo vantajoso em relação aos sistemas convencionais em função do menor custo do preparo e redução nas perdas de água e solo.

Segundo FIGUEIREDO \& MAGALHÃES (1992), o escarificador é um equipamento adequado para o preparo reduzido do solo, com menor revolvimento e menor incorporação de restos vegetais de culturas, protegendo sua superfície e melhorando a infiltração de água.

Segundo LOPES et al. (2003a), o consumo de combustível de um trator 4x2 TDA, com $89 \mathrm{~kW}(121 \mathrm{cv})$ no motor, em operação de preparo do solo com escarificador de arrasto conjugado com rolo destorroador e discos de corte, 7 hastes, ponteira sem asa com 0,07 $\mathrm{m}$ de largura, trabalhando a $0,3 \mathrm{~m}$ de profundidade média, tem os seguintes valores: consumo horário $\left(13,7 \mathrm{~kg} \mathrm{~h}^{-1}\right)$ e consumo específico $\left(554 \mathrm{~g} \mathrm{kWh}^{-1}\right)$. Os autores concluíram que o consumo de combustível e o desempenho do trator foram influenciados pela lastragem do trator e pela carga imposta na barra de tração.

SUMMERS et al. (1986), ao analisarem funções relativas à variação da força de tração média com a velocidade, para alguns equipamentos de preparo do solo, observaram que o esforço tratório variou linearmente com a velocidade, para equipamentos como subsoladores, grades de discos e escarificadores. Os autores observaram, ainda, que pequenas mudanças na profundidade de preparo ou na velocidade de deslocamento afetaram significativamente o consumo horário de combustível e a energia requerida.

O presente trabalho teve por objetivo avaliar o desempenho operacional de um protótipo "Aerossolo", tracionado por trator agrícola, em função da lastragem do equipamento e do ângulo entre as seções. 


\section{MATERIAL E MÉTODOS}

O trabalho foi conduzido em condição de campo, nas dependências do Laboratório de Máquinas e Mecanização Agrícola (LAMMA), do Departamento de Engenharia Rural, UNESP Jaboticabal - SP. A localização geográfica da área de realização dos ensaios é definida pelas coordenadas $21^{\circ} 15^{\prime}$ latitude sul e $48^{\circ} 18^{\prime}$ longitude oeste, sendo a altitude média de $570 \mathrm{~m}$, e clima tropical úmido com estação chuvosa no verão e seca no inverno (Aw), de acordo com a classificação de Köeppen.

O solo da área experimental foi classificado como Latossolo Vermelho eutroférrico típico (EMBRAPA, 1999), com relevo suave ondulado e declividade de 7\%. Apresentou teor médio de água, nos dias dos ensaios, de 220 e $280 \mathrm{~g} \mathrm{~kg}^{-1}$ no perfil de $0-0,1$ e $0,1-0,2 \mathrm{~m}$ de profundidade, respectivamente. A análise granulométrica da camada de $0-0,2 \mathrm{~m}$ para argila, silte, areia fina e areia grossa foi 510; 290; 100 e $100 \mathrm{~g} \mathrm{~kg}^{-1}$, respectivamente, sendo o mesmo considerado como textura argilosa. A superfície do solo estava $100 \%$ coberta por restos da cultura do milho, o que resultou em $2.200 \mathrm{~kg}$ de massa seca por hectare.

O protótipo (Figura 1) trata-se de equipamento construído inicialmente com a finalidade de recuperar pastagens degradadas, favorecendo a aeração do solo; em função disso, foi patenteado como Aerossolo.

Neste trabalho, procurou-se avaliá-lo como equipamento de preparo reduzido do solo, por realizar o preparo primário do solo por meio das lâminas, e o preparo secundário, por meio do rolo destorroador duplo. Tal implemento é constituído por comando hidráulico, cabeçalho com luva telescópica para regulagem longitudinal, duas seções dispostas lateralmente, contando cada seção com sete conjuntos de lâminas com quatro lâminas cada, dispostas helicoidalmente, com apenas uma mobilizando o solo por vez. Os conjuntos de lâminas são fixados em um eixo giratório, que realiza o movimento pela ação do deslocamento. As lâminas têm $0,24 \mathrm{~m}$ de comprimento e $0,04 \mathrm{~m}$ de espessura; como opcional, podem ser adicionados lastros de concreto, que acompanham o equipamento, para aumentar a profundidade de trabalho, rodas de transporte e rolo destorroador duplo para conferir o nivelamento da superfície. Como principais regulagens, têm-se a adição de lastros (máximo de $1.307 \mathrm{~kg}$ ) e cinco variações do ângulo das seções $\left(0 ; 4 ; 7 ; 11\right.$ e $\left.14^{\circ}\right)$.

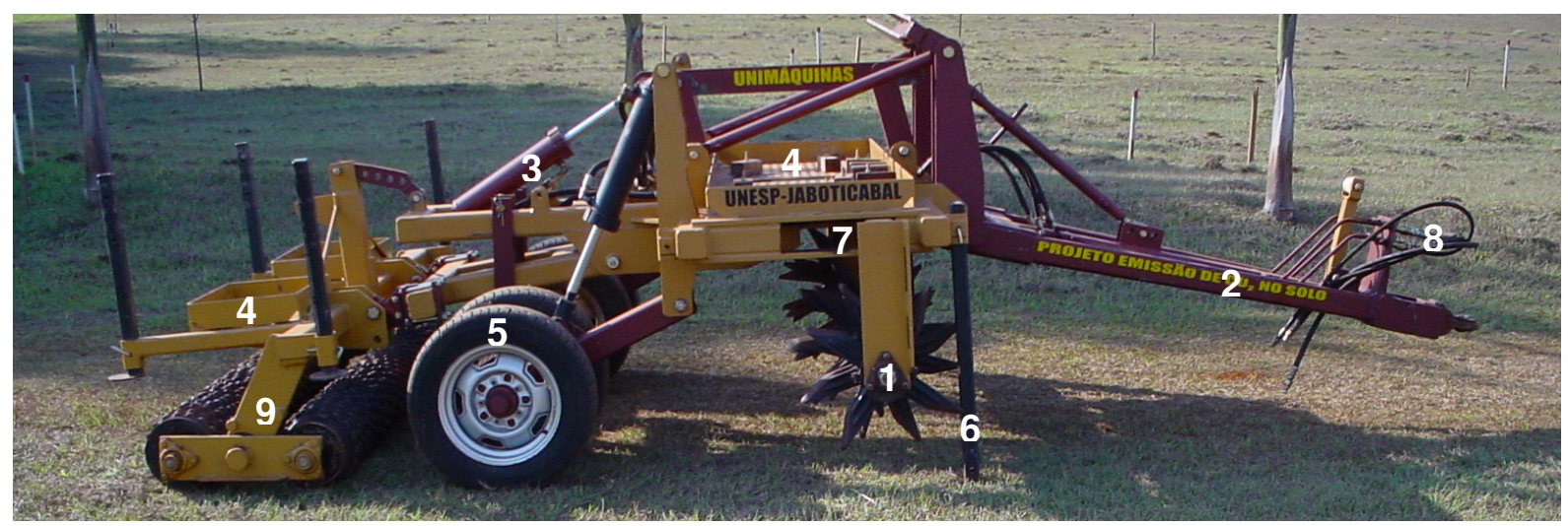

FIGURA 1. Vista geral do protótipo "Aerossolo". Overview of the "Aerossolo" prototype.

1 - Eixo das seções;

2 - Cabeçalho;

3 - Cilindro hidráulico;

4 - Local dos lastros de concreto;

5 - Rodas de transporte;
6 - Apoio fixo;

7 - Ponto de regulagem do ângulo das seções;

8 - Mangueiras hidráulicas;

9 - Rolo destorroador duplo.

Para tracionar o equipamento, foi utilizado um trator da marca Valtra, modelo BM100, 4X2 TDA, com 73,6 kW (100 cv) de potência no motor, trabalhando a $2.300 \mathrm{rpm}$, sendo instrumentado 
para a realização do teste, conforme descrito em LOPES (2006). Utilizou-se como combustível a proporção $\mathrm{B}_{5}, 5 \%$ de Biodiesel e $95 \%$ de diesel. Tal Biodiesel foi produzido no Laboratório de Desenvolvimento de Tecnologias Limpas, LADETEL - USP, Ribeirão Preto - SP.

O delineamento experimental foi em blocos casualizados, esquema fatorial $3 \times 3$, com nove tratamentos e quatro repetições. As combinações dos tratamentos deram-se por três condições de lastragem ( $\mathrm{L} 1=0 \mathrm{~kg}$ de lastro; $\mathrm{L} 2=960 \mathrm{~kg}$ de lastro, e L3 $=1.307 \mathrm{~kg}$ de lastro) e três ângulos entre as seções $\left(\mathrm{A} 1=0^{\circ} ; \mathrm{A} 2=7^{\circ}\right.$, e A3 $\left.=14^{\circ}\right)$.

Acrescenta-se que, em todas as parcelas, a estabilização do conjunto deu-se pelo início do movimento do trator num espaço de $15 \mathrm{~m}$ antes de iniciar as medições. Quando o referencial do trator, centro do rodado traseiro, coincidia com a primeira baliza, foi acionado o sistema de aquisição de dados, sendo esse procedimento interrompido quando se decorriam os $30 \mathrm{~m}$ de comprimento da parcela, momento em que o centro do rodado traseiro coincidia com a segunda baliza.

A profundidade de penetração das lâminas foi determinada de maneira direta, por meio de haste metálica graduada em milímetros, sendo tal operação realizada logo após a passagem do aerossolo, pressionando-se a haste no solo até atingir o solo não mobilizado. A cobertura do solo foi determinada antes e após a passagem do aerossolo, utilizando-se do método da trena, descrito por LAFLEN et al. (1981), em que cada marca da trena coincidente com resíduos vegetais na superfície do solo foi considerada um ponto percentual de cobertura. Em todas as parcelas experimentais, foram efetuadas duas leituras em diagonais cruzadas.

A velocidade real de deslocamento e a força de tração foram determinadas diretamente, utilizando-se de unidade de radar e de célula de carga, respectivamente.

A potência média na barra de tração foi determinada de forma indireta, utilizando-se da seguinte equação:

$$
\mathrm{PB}=\mathrm{FT} \mathrm{V}
$$

em que,

$\mathrm{PB}$ - potência na barra de tração, $\mathrm{kW}$;

FT - força média de tração na barra, $\mathrm{kN}$, e

$\mathrm{V}$ - velocidade real de deslocamento, $\mathrm{m} \mathrm{s}^{-1}$.

A capacidade de campo operacional foi determinada com base na largura de trabalho real do aerossolo, na velocidade real de deslocamento do conjunto e na eficiência de campo do aerossolo, que, para este trabalho, foi adotada como 75\%, segundo BALASTREIRE (1987). A largura de trabalho real foi a média de três passadas do aerossolo, sendo medida com trena graduada em milímetros. Os valores foram de 2,43; 2,33 e 2,21 m, para o aerossolo trabalhando com ângulo das seções de $0 ; 7$ e $14^{\circ}$, respectivamente.

Para o cálculo da capacidade de campo operacional, utilizou-se da eq.(2):

$$
\mathrm{CCO}=\frac{0,75 \mathrm{~L} \mathrm{v}}{10}
$$

em que,

CCO - capacidade de campo operacional, ha $\mathrm{h}^{-1}$;

0,75 - eficiência de campo do aerossolo;

$\mathrm{v}$ - velocidade real de deslocamento, $\mathrm{km} \mathrm{h}^{-1}$;

$\mathrm{L}$ - largura real de trabalho do implemento, $\mathrm{m}, \mathrm{e}$

10 - fator de conversão para ha $\mathrm{h}^{-1}$.

Para medir o consumo de combustível, foi utilizado um protótipo desenvolvido por LOPES et al. (2003b). Para calcular o consumo de combustível ponderal, foi necessário determinar a 
densidade em função da temperatura do combustível no momento do ensaio, e da proporção de biodiesel de soja etílico destilado no combustível. Tal equação foi desenvolvida por LOPES (2006):

$$
\mathrm{D}=850-0,813 \mathrm{~T}+0,306 \mathrm{P}+0,0022 \mathrm{~T}^{2}-0,0007 \mathrm{P}^{2}-0,0007 \mathrm{~T} \mathrm{P}+0,0011 \mathrm{P}^{2}
$$

em que,

D - densidade do combustível, $\mathrm{g} \mathrm{L}^{-1}$

$\mathrm{T}$ - temperatura do combustível, ${ }^{\circ} \mathrm{C}$, e

P - proporção de Biodiesel, \%.

Com base no volume consumido e no tempo de percurso em cada parcela, foi determinado o consumo horário volumétrico, utilizando-se da eq. (4):

$$
\mathrm{Chv}=3,6\left(\frac{\mathrm{Va}-\mathrm{Vr}}{\mathrm{t}}\right)
$$

em que,

3,6 - fator de conversão;

Chv - consumo horário volumétrico, $\mathrm{L} \mathrm{h}^{-1}$;

Va - volume de alimentação de combustível na entrada da bomba injetora, mL;

$\mathrm{Vr}$ - volume total retornado dos bicos e da bomba injetora, $\mathrm{mL}$, e

$\mathrm{t}$ - tempo de percurso na parcela, $\mathrm{s}$.

Para determinar o consumo horário ponderal, utilizou-se da eq. (5):

$$
\mathrm{Chm}=\left(\frac{3,6}{1.000 \mathrm{t}}\right)[(\mathrm{Va} \mathrm{Da})-(\mathrm{Vr} \text { Dr })]
$$

em que,

Chm - consumo horário ponderal, $\mathrm{kg} \mathrm{h}^{-1}$;

3,6 e 1.000 - fatores de conversão;

$\mathrm{t}$ - tempo de percurso na parcela, $\mathrm{s}$;

$\mathrm{Da}$ - densidade do combustível no momento da alimentação, $\mathrm{g} \mathrm{L}^{-1}$;

Dr - densidade do combustível retornado pelos bicos e pela bomba injetora, $\mathrm{g} \mathrm{L}^{-1}$;

$\mathrm{Va}$ - volume de alimentação de combustível na entrada da bomba injetora, $\mathrm{mL}, \mathrm{e}$

$\mathrm{Vr}$ - volume total retornado dos bicos e da bomba injetora, $\mathrm{mL}$.

Para o consumo operacional, expresso em volume por unidade de área trabalhada, utilizou-se da eq. (6):

$$
\mathrm{CO}=\frac{\mathrm{Chv}}{\mathrm{CCO}}
$$

em que,

$\mathrm{CO}$ - consumo operacional, $\mathrm{L} \mathrm{ha}^{-1}$;

Chv - consumo horário volumétrico, $\mathrm{L} \mathrm{h}^{-1}$, e

$\mathrm{CCO}$ - capacidade de campo operacional, ha $\mathrm{h}^{-1}$.

Os dados foram submetidos à análise de variância e ao teste de comparação de médias de Tukey, a 5\% de probabilidade, conforme recomendação de PIMENTEL GOMES (1987) e BANZATTO \& KRONKA (1995).

\section{RESULTADOS E DISCUSSÃO}

Os resultados foram apresentados na forma de tabelas. Ressalta-se que a interpretação dos mesmos inicia-se pelo teste de $\mathrm{F}$ da interação; porém, no presente trabalho, não se observou 
dependência de um fator em relação ao outro, o que implica inexistência de tabela de desdobramento.

A síntese da análise estatística foi apresentada para grupos de variáveis nas Tabelas 1; 2 e 3. Nessas tabelas, os dados referentes aos fatores ângulo das seções e lastragem do aerossolo representam médias de 12 observações.

\section{Profundidade de trabalho}

Na Tabela 1, observa-se que essa variável no fator lastragem foi maior $(0,15 \mathrm{~m})$ quando o aerossolo estava totalmente lastrado $(\mathrm{L} 3=1.307 \mathrm{~kg})$, ressaltando-se que não houve diferença de L1 (sem lastro) para L2 (960 kg), quando a profundidade ficou em 0,13 m. Com relação ao ângulo das seções, observou-se que, à medida que se aumentou a angulação de 0 para $14^{\circ}$, foi incrementada a profundidade de trabalho em $0,04 \mathrm{~m}$. É possível relacionar essa variável com as regulagens do equipamento, assim como acontece com as grades niveladoras e aradoras (ORTIZ-CAÑAVATE, 1980).

Nota-se, ainda, que, em todas as regulagens avaliadas, a profundidade de preparo não ultrapassou $0,15 \mathrm{~m}$, valor esse considerado pequeno para culturas com sistema radicular mais profundo, porém são necessários novos estudos para avaliar o desenvolvimento de diferentes culturas em solo preparado com esse equipamento nas várias regulagens disponíveis.

TABELA 1. Síntese da análise de variância e do teste de médias para a cobertura do solo e profundidade de trabalho. Synthesis of analysis of variance and averages test for the cover soil and work depth.

\begin{tabular}{ccc}
\hline \multirow{2}{*}{ Fatores } & Profundidade de Trabalho & Cobertura do Solo \\
\cline { 2 - 3 } & $\mathrm{m}$ & $\%$ \\
\hline Lastragem (L) & $0,13 \mathrm{~B}$ & $71 \mathrm{~A}$ \\
L1 & $0,13 \mathrm{~B}$ & $61 \mathrm{~B}$ \\
L2 & $0,15 \mathrm{~A}$ & $50 \mathrm{C}$ \\
L3 & & \\
Ângulo (A) & $0,11 \mathrm{C}$ & $72 \mathrm{~A}$ \\
A1 & $0,13 \mathrm{~B}$ & $56 \mathrm{~B}$ \\
A2 & $0,15 \mathrm{~A}$ & $54 \mathrm{~B}$ \\
A3 & & \\
Teste F & $9,09^{* *}$ & $14,01^{* *}$ \\
L & $75,48^{* *}$ & $11,66^{* *}$ \\
A & $1,65^{\mathrm{NS}}$ & $0,85^{\mathrm{NS}}$ \\
LxA & 5,34 & 16,02 \\
\hline C.V.\% & & \\
\hline
\end{tabular}

Em cada coluna, para cada fator, médias seguidas de mesmas letras maiúsculas não diferem entre si, pelo teste de Tukey, a 5\% de probabilidade. ${ }^{\mathrm{NS}}$ - não significativo; $* *$ - significativo $(\mathrm{P}<0,01)$; C.V.: coeficiente de variação

\section{Cobertura do solo}

Pela Tabela 1, observa-se que, no fator lastragem, a cobertura do solo de $70 \%$ foi significativamente maior ( $\mathrm{p}<0,01)$ quando o aerossolo estava na condição L1 (sem lastro) e menor quando o aerossolo estava com lastragem máxima de $1.307 \mathrm{~kg}(50 \%)$. Para o fator ângulo das seções, nota-se que, quando o ângulo foi de $0^{\circ}$, a cobertura do solo foi maior. Esses maiores valores de cobertura proporcionados pela redução da lastragem e pelo menor ângulo das seções aconteceram em virtude da menor mobilização do solo causada pelas lâminas do equipamento. Tal afirmação pode ser confirmada com a variável profundidade de trabalho. Comparando-se esses resultados com os de um escarificador, recomendado para o sistema conservacionista, nota-se que o valor de $70 \%$ de cobertura do solo obtido por CARVALHO FILHO et al. (2007) e BOLLER \& GAMERO (1997) é semelhante aos valores encontrados para o aerossolo sem lastro. 


\section{Velocidade de deslocamento}

Pela Tabela 2, verifica-se que, no fator lastragem, a velocidade de deslocamento foi maior para a condição L1 (sem lastro), sendo L2 $(960 \mathrm{~kg})$ semelhante a L3 $(1.307 \mathrm{~kg})$. Analisando-se o ângulo entre as seções, a velocidade foi significativamente maior $(\mathrm{p}<0,01)$ para $A=0^{\circ}$ e $7^{\circ}$, e menor para $14^{\circ}$. Entende-se que a redução de velocidade foi em virtude do aumento da força de tração e essa, por sua vez, foi influenciada pela maior profundidade de penetração das lâminas.

TABELA 2. Síntese da análise de variância e do teste de médias para velocidade, força de tração, potência na barra de tração e capacidade de campo operacional (CCO). Synthesis of analysis of variance and averages test for speed, traction force, potency on the drawbar and operational field capacity (CCO).

\begin{tabular}{|c|c|c|c|c|}
\hline Fatores & $\begin{array}{c}\text { Velocidade } \\
\mathrm{km} \mathrm{h}^{-1}\end{array}$ & $\begin{array}{c}\text { Força de Tração } \\
\text { kN }\end{array}$ & $\begin{array}{c}\text { Potência na Barra } \\
\mathrm{kW}\end{array}$ & $\begin{array}{l}\mathrm{CCO} \\
\mathrm{ha} \mathrm{h}^{-1}\end{array}$ \\
\hline \multicolumn{5}{|c|}{ Lastragem (L) } \\
\hline L1 & $6,2 \mathrm{~A}$ & $14,6 \mathrm{~A}$ & $25,1 \mathrm{~A}$ & $1,1 \mathrm{~A}$ \\
\hline L2 & $6,0 \mathrm{~B}$ & $19,1 \mathrm{~B}$ & $31,8 \mathrm{~B}$ & $1,0 \mathrm{~B}$ \\
\hline L3 & $5,9 \mathrm{~B}$ & $20,9 \mathrm{C}$ & $34,3 \mathrm{C}$ & $1,0 \mathrm{~B}$ \\
\hline \multicolumn{5}{|c|}{ Ângulo (A) } \\
\hline A1 & $6,1 \mathrm{~A}$ & $16,5 \mathrm{~A}$ & $28,0 \mathrm{~A}$ & $1,1 \mathrm{~A}$ \\
\hline $\mathrm{A} 2$ & $6,0 \mathrm{~A}$ & $18,2 \mathrm{~B}$ & $30,3 \mathrm{~B}$ & $1,1 \mathrm{~A}$ \\
\hline A3 & $5,8 \mathrm{~B}$ & $19,9 \mathrm{C}$ & $32,3 \mathrm{C}$ & $1,0 \mathrm{~B}$ \\
\hline \multicolumn{5}{|l|}{ Teste F } \\
\hline $\mathrm{L}$ & $16,12 * *$ & $278,54 * *$ & $239,07 * *$ & $19,30 * *$ \\
\hline A & $13,02 * *$ & $75,42 * *$ & $51,22 * *$ & $109,10 * *$ \\
\hline LxA & $1,01^{\mathrm{NS}}$ & $1,13^{\mathrm{NS}}$ & $0,53^{\mathrm{NS}}$ & $1,63^{\mathrm{NS}}$ \\
\hline C.V.\% & 2,46 & 3,72 & 3,41 & 2,41 \\
\hline
\end{tabular}

Em cada coluna, para cada fator, médias seguidas de mesmas letras maiúsculas não diferem entre si, pelo teste de Tukey, a 5\% de probabilidade. ${ }^{\mathrm{NS}}$ - não significativo; ${ }^{*} *$ - significativo $(\mathrm{P}<0,01) ; \mathrm{C} . \mathrm{V}$.: coeficiente de variação

\section{Capacidade de campo operacional}

Pela Tabela 2, nota-se que a capacidade de campo operacional foi $10 \%$ superior para o aerossolo sem lastro, ou seja, na condição L1. Com relação ao fator ângulo das seções, observa-se que, na condição de $14^{\circ}$, resultou na menor capacidade de campo operacional em função da menor largura de trabalho observada nessa regulagem. O recurso de angulação das seções com o objetivo de aumentar a profundidade de trabalho também é utilizado nas grades de arrasto (FURLANI et al., 1999).

\section{Força de tração e potência na barra}

Pela Tabela 2, verifica-se que a força de tração e a potência na barra tiveram comportamentos semelhantes, ou seja, cresceram com a adição de lastro e com o aumento do ângulo das seções. Esse comportamento está relacionado com a alteração na profundidade de trabalho em função das regulagens permitidas pelo aerossolo. Os resultados para o aerossolo sem lastro são equivalentes aos encontrados por GROTTA et al. (2008), que ensaiaram grade pesada com largura de trabalho de $1,63 \mathrm{~m}$ e velocidade de $6,0 \mathrm{~km} \mathrm{~h}^{-1}$.

Nota-se, ainda, que a mudança no ângulo de 0 para $14^{\circ}$ ocasionou aumento na profundidade de trabalho de $0,04 \mathrm{~m}$, elevando a força de tração em $3,4 \mathrm{kN}$ e a potência em $4,1 \mathrm{~kW}$.

\section{Consumo horário volumétrico de combustível}

Pela Tabela 3, observa-se que, à medida que se adicionou lastro ao equipamento, aumentou o consumo volumétrico, sendo esse $25 \%$ maior na condição L3, comparado à L1. Em relação ao ângulo das seções, o menor valor deu-se para $0^{\circ}$; entretanto, essa variável foi semelhante para 7 e 
$14^{\circ}$. Tal comportamento é explicado pelo aumento da força de tração relacionada às regulagens realizadas. Tais resultados são equivalentes com aqueles encontrados por FURLANI (2000) e LEVIEN et al. (2003), trabalhando com grades de arrasto e profundidades semelhantes.

TABELA 3. Síntese da análise de variância e do teste de médias para o consumo horário (volumétrico - Chv e ponderal - Chm) e consumo operacional (CO). Synthesis of analysis of variance and averages test for the hour consumption (volumetric Chv and ponderal - $\mathrm{Chm}$ ) and operational consumption (CO).

\begin{tabular}{cccc}
\hline \multirow{2}{*}{ Fatores } & $\mathrm{Chv}$ & $\mathrm{Chm}$ & $\mathrm{CO}$ \\
\cline { 2 - 4 } & $\mathrm{L} \mathrm{h}^{-1}$ & $\mathrm{~kg} \mathrm{~h}^{-1}$ & $\mathrm{~L} \mathrm{ha}^{-1}$ \\
\hline Lastragem (L) & & & $10,8 \mathrm{~A}$ \\
L1 & $11,6 \mathrm{~A}$ & $9,6 \mathrm{~A}$ & $12,8 \mathrm{~B}$ \\
L2 & $13,2 \mathrm{~B}$ & $11,0 \mathrm{~B}$ & $14,3 \mathrm{C}$ \\
L3 & $14,5 \mathrm{C}$ & $12,1 \mathrm{C}$ & $11,2 \mathrm{~A}$ \\
Ângulo (A) & & & $12,5 \mathrm{~B}$ \\
A1 & $12,5 \mathrm{~A}$ & $10,4 \mathrm{~A}$ & $14,2 \mathrm{C}$ \\
A2 & $13,2 \mathrm{~B}$ & $11,0 \mathrm{~B}$ & $77,90^{* *}$ \\
A3 & $13,7 \mathrm{~B}$ & $11,4 \mathrm{~B}$ & $54,43^{* *}$ \\
Teste F & & $0,44^{\mathrm{NS}}$ \\
L & $66,08^{* *}$ & $68,05^{* *}$ & 5,49 \\
AxA & $10,89^{* *}$ & $11,20^{* *}$ & $0,21^{\mathrm{NS}}$ \\
\hline C.V.\% & $0,17^{\mathrm{NS}}$ & $4,75^{*}$ & .
\end{tabular}

Em cada coluna, para cada fator, médias seguidas de mesmas letras maiúsculas não diferem entre si, pelo teste de Tukey, a 5\% de probabilidade. ${ }^{\mathrm{NS}}$ - não significativo; $* *$ - significativo $(\mathrm{P}<0,01)$; C.V .: coeficiente de variação

\section{Consumo horário ponderal de combustível}

De acordo com a Tabela 3, nota-se que o comportamento do consumo horário ponderal, corrigido pela densidade do combustível no momento do ensaio, foi semelhante ao volumétrico. Tal situação evidencia que a temperatura, no momento do ensaio, não variou significativamente a ponto de influenciar na densidade do combustível de um ensaio para o outro.

\section{Consumo operacional de combustível}

Pela Tabela 3, verifica-se que o consumo operacional aumentou tanto com a adição de lastros quanto com o aumento do ângulo das seções. Esse comportamento está relacionado com a alteração na profundidade de trabalho, velocidade de deslocamento e largura de trabalho resultante das regulagens realizadas no equipamento. Resultados semelhantes foram encontrados por FURLANI et al. (1999) quando ensaiaram grade niveladora, trabalhando com velocidade e largura equivalentes.

\section{CONCLUSÕES}

O acréscimo de lastros no aerossolo, bem como o aumento do ângulo das seções proporcionaram menor cobertura do solo.

$\mathrm{O}$ aerossolo desprovido de lastros e com ângulo das seções de $0^{\circ}$ e $7^{\circ}$ resultou na maior velocidade de deslocamento e, consequentemente, na maior capacidade de campo operacional.

A força de tração e a potência na barra aumentaram em virtude da adição de lastros e da maior angulação da seção, em função do aumento na profundidade de trabalho.

Os consumos volumétrico, ponderal e operacional aumentaram com a adição de lastros no aerossolo e com o aumento do ângulo das seções, uma vez que essas regulagens exigiram maior potência na barra de tração. 
O ângulo de $7^{\circ}$ é o mais recomendado para o aerossolo, pois, nessa regulagem, o trator teve consumo intermediário e máxima capacidade de campo operacional.

\section{AGRADECIMENTOS}

À FAPESP e à FUNDUNESP, pelo financiamento da instrumentação; à Coopercitrus e à Valtra do Brasil, pela concessão dos tratores de testes; à UNIMÁQUINAS, pela concessão do Aerossolo.

\section{REFERÊNCIAS}

ASAE. AMERICAN SOCIETY OF AGRICULTURAL ENGINEERS. Terminoly and definitions for agricultural tillage implements. In: practices data. St Joseph, 1997. p. 254-275. . ASAE standards 1997: standards engineering

BALASTREIRE, L.A. Máquinas agrícolas. São Paulo: Manole, 1987. 307 p.

BANZATTO, D.A.; KRONKA, S.N. Experimentação agrícola. Jaboticabal: FUNEP, 1995. 247 p.

BOLLER, W.; GAMERO, C.A. Estimativa dos custos econômicos e energéticos de sistemas de preparo do solo para a cultura do feijão. Energia na Agricultura, Botucatu, v.12, n.2, p.26-38, 1997.

CARVALHO FILHO, A.; SILVA, R.P.; CENTURION, J.F.; CARVALHO, L.C.C.; LOPES, A. Agregação de um Latossolo Vermelho submetido a cinco sistemas de preparo do solo em Uberaba MG. Engenharia Agrícola, Jaboticabal, v. 27, n. 1, p. 317-325, 2007.

DALLMEYER, A.U. Eficiência energética e operacional de equipamentos conjugados de preparo do solo. 1994. 157 f. Tese (Doutorado em Energia na Agricultura) - Faculdade de Ciências Agronômicas, Universidade Estadual Paulista, Botucatu, 1994.

EMBRAPA. EMPRESA BRASILEIRA DE PESQUISA AGROPECUÁRIA. Centro Nacional de Pesquisas de Solos. Sistema brasileiro de classificação de solos. Brasília, 1999. 412 p.

FIGUEIREDO, P.R.A.; MAGALHÃES, P.S.G. Otimização do desempenho de uma máquina de preparo mínimo do solo. In: CONGRESSO BRASIELIRO DE ENGENHARIA AGRÍCOLA, 21., 1992, Santa Maria. Anais... Santa Maria: Sociedade Brasileira de Engenharia Agrícola, 1992. p.1.405-1.418.

FURLANI, C.E.A. Efeito do preparo do solo e do manejo da cobertura de inverno na cultura do feijoeiro (Phaseolus vulgaris L.). 2000. $221 \mathrm{f}$. Tese (Doutorado em Energia na Agricultura) Faculdade de Ciências Agronômicas, Universidade Estadual Paulista, Botucatu, 2000.

FURLANI, C.E.A.; LEVIEN, R.; GAMERO, C.A. Consumo de combustível e capacidade operacional de preparos do solo em diferentes manejos do consórcio aveia preta (Avena strigosa) e nabo forrageiro (Raphanus sativus). In: CONGRESSO BRASILEIRO DE ENGENHARIA AGRÍCOLA, 28., 1999, Pelotas. Anais... Jaboticabal: Sociedade Brasileira de Engenharia Agrícola, 1999. 1 CD-ROM.

GADANHA JÚNIOR, C.D.; MOLIN, J.P.; COELHO, J.L.D.; YAHN, C.H.; TOMINORI, S.M.A. Máquinas e implementos agrícolas do Brasil. São Paulo: Instituto de Pesquisas Tecnológicas do Estado de São Paulo, 1991. 468 p.

GROTTA, D.C.C.; LOPES, A.; FURLANI, C.E.A.; SILVA, R.P.; REIS, G.N.; CORTEZ, J.W. Biodiesel etílico filtrado de óleo residual de soja: desempenho de um trator agrícola na operação de gradagem. Acta Scientiarum Agronomy, Maringá, v.30, n.2, p.135-138, 2008.

HAKANSON, I. Soil tillage for crop production and for protection of soil and enviromental quality: a Scandinavium view-point. Soil \& Tillage Research, Amsterdam, n.30, n.2, p.109-124, 1994.

LAFLEN, J. M.; AMEMIYA, A.; HINTZ, E. A. Measuring crop residue cover. Journal of Soil and Water Conservation, Iowa, v.36, n.6, p.341-343, 1981. 
LEVIEN, R.; GAMERO, C.A.; FURLANI, C.E.A. Preparo convencional e reduzido em solo argiloso em diferentes condições de cobertura de inverno. Engenharia Agrícola, Jaboticabal, v.23, n.2, p.277-289, 2003.

LOPES, A. Biodiesel em trator agrícola: desempenho e opacidade. 2006. 158 f. Tese (Livre-docência em Mecanização Agrícola) - Faculdade de Ciências Agrárias e Veterinárias, Universidade Estadual Paulista, Jaboticabal, 2006.

LOPES, A.; FURLANI, C.E.A.; SILVA, R.P. Desempenho de um protótipo para medição de combustível em tratores. Revista Brasileira de Agroinformática, Viçosa - MG, v.5, n.1. p.24-31, 2003b.

LOPES, A.; LANÇAS, K.P.; FURLANI, C.E.A.; NAGAOKA, A.K.; CASTRO NETO, P.; GROTTA, D.C.C. Consumo de combustível de um trator em função do tipo de pneu, da lastragem e da velocidade de trabalho. Revista Brasileira de Engenharia Agrícola e Ambiental, Campina Grande, v.7, n.2, p.375-379, 2003a.

ORTIZ-CAÑAVATE, J. Las maquinas agrícolas y su aplicación. Madrid: Mundi-Prensa, 1980. $490 \mathrm{p}$.

PIMENTEL GOMES, F. A estatística moderna na pesquisa agropecuária. 3.ed. Piracicaba: Associação Brasileira para Pesquisa da Potassa e do Fosfato, 1987. 162 p.

SUMMERS, H.R.; HELLWING, R.E.; MONROE, G.E. Measuring implement power requeriments from tractor fuel consumption. Transaction of the ASAE, St. Joseph, v.29, n.1, p.85-89, 1986. 